\title{
The Inhibition Effect of Polyaspartic Acid and Its Mixed Inhibitor on Mild Steel Corrosion in Seawater Wet/Dry Cyclic Conditions
}

\author{
Xiumin $M a^{1, *}$, Bei Qian ${ }^{2}$, jie zhang ${ }^{1}$, Weichen $X u^{l}$, Quantong Jiang ${ }^{1}$, Meng Zheng ${ }^{1}$, Fubin Ma ${ }^{1}$, \\ Baorong Hou ${ }^{l}$ \\ ${ }^{1}$ Institute of Oceanology, Chinese Academy of Sciences, 7 Nanhai Road, Qingdao 266071, PR China \\ ${ }^{2}$ Qingdao Agricultural University, Qingdao 266109, China \\ "E-mail: xma@qdio.ac.cn
}

doi: $10.20964 / 110403024$

Received: 7 December 2015 / Accepted: 8 February 2015 / Published: 1 March 2015

\begin{abstract}
The inhibition effects of polyaspartic acid (PASP) and the mixed inhibitor (50mg/L PASP, 100mg/L $\mathrm{Na}_{2} \mathrm{WO}_{4}, 100 \mathrm{mg} / \mathrm{L} \mathrm{ZnSO} \mathrm{Zn}_{4} 7 \mathrm{H}_{2} \mathrm{O}$ ) on mild steel corrosion in seawater wet/dry cyclic conditions were studied via weight loss and electrochemical methods. The polarization curves show that the inhibition efficiency is $72.4 \%$ in the presence of PASP, and rises up to $92.6 \%$ after the addition of the mixted inhibitor. Scanning electron microscopy (SEM), X-ray diffraction and Fourier transform infrared reflection were performed to study the corrosion inhibition effect. According to the results of SEM, the metal surface immersed in the mixed inhibitor was better protected than that in PASP due to the formation of a protective film.
\end{abstract}

Keywords: Mild steel, EIS, SEM, XRD, Neutral inhibition

\section{$\underline{\text { FULL TEXT }}$}

(C) 2016 The Authors. Published by ESG (www.electrochemsci.org). This article is an open access article distributed under the terms and conditions of the Creative Commons Attribution license (http://creativecommons.org/licenses/by/4.0/). 